\title{
Quantitative Assessment of Chronic Skin Reactions Including Erythema and Pigmentation after Breast Conserving Therapy
}

\author{
Miho Kawashima1*, Miwako Nozaki', Kazuhiro Komazaki', Ryuko Yamamuro1, \\ Kazuo Ishizuna ${ }^{2}$, Makoto Kojima ${ }^{2}$ \\ ${ }^{1}$ Department of Radiology, Dokkyo Medical University Koshigaya Hospital, Saitama, Japan \\ ${ }^{2}$ Breast Center, Dokkyo Medical University Koshigaya Hospital, Saitama, Japan \\ Email: "mihokw052307070624@gmail.com
}

Received 10 June 2016; accepted 5 July 2016; published 8 July 2016

Copyright (C) 2016 by authors and Scientific Research Publishing Inc.

This work is licensed under the Creative Commons Attribution International License (CC BY).

http://creativecommons.org/licenses/by/4.0/

(c) (i) Open Access

\begin{abstract}
Purpose: To evaluate long-term skin reactions following breast-conserving therapy by using the melanin-erythema index meter. Patients and Methods: 164 patients were followed for at least three years after breast-conserving therapy. For both the erythema and the melanin indices, the ratio of the irradiated-side index to the non-irradiated-side index was calculated. The time course of index ratios alternation was examined. Influences from additional therapies and patients' age were also evaluated. Result: Both erythema and melanin index ratios of the breast skin were recovered to pre-radiation level three years after radiotherapy. However, both index ratios of the area administrated with 10-Gy boost irradiation were still high even after five years after radiotherapy. Endocrine therapy, chemotherapy and age had no significant influence on skin color reactions three years after radiotherapy. Conclusion: Quantitative assessment using the melaninerythema index meter demonstrated that chronic skin reactions following breast conserving therapy had recovered to pre-radiation level for three years after irradiation except for the 10-Gy boost irradiated area.
\end{abstract}

\section{Keywords}

Breast Cancer, Erythema Index, Melanin Index, Breast-Conserving Therapy

\footnotetext{
${ }^{*}$ Corresponding author.
} 


\section{Introduction}

The morbidity of breast cancer has been increasing in Japan, and breast cancer has become the first common cancer among Japanese women. Breast conserving therapy is the treatment of choice for early breast cancers [1] [2] and the number of breast cancer patients undergoing breast conserving therapy has been increasing in Japan [3]. The role of radiotherapy is considered important for local control and post-operative radiotherapy is strongly recommended. For good prognosis, it is crucial to assess quality of life and adverse effects caused by surgery and irradiation in addition to survival or recurrent rates [4] [5]. Skin changes are important factors in adverse effects. Adverse effects of radiotherapy on the skin are as follows: erythema, damages of sweat gland, dry desquamation and moist desquamation as acute reactions; hyperpigmentation, dyspigmentation, telangiectasia, atrophy, ulcer and necrosis as chronic adverse reactions [6]-[8]. There are some criteria to evaluate radiation adverse effects [9] [10]; however, there have not been sufficient studies objectively assessing skin reactions following radiotherapy. We have already reported an objective method to assess acute skin reactions after breast conserving therapy using the melanin-erythema index meter (Mexameter ${ }^{\circledR}$ MX 18) [11]. In this study, we used this method and evaluated the chronic skin reactions following breast conserving therapy.

\section{Patients and Methods}

\subsection{Patients}

The patients' characteristics are shown in Table 1. There were 164 patients who underwent radiotherapy following breast conserving surgery in our radiology department from January 2007 to December 2009 and were followed periodically on an outpatient basis for 3 years or more after radiotherapy. Seventy of these patients

\begin{tabular}{|c|c|c|c|}
\hline Age & Median & 57.5 years old & $\begin{array}{c}\text { (range: } 33-79 \\
\text { years) }\end{array}$ \\
\hline & $\geq 50$ years & & 121 \\
\hline & $<50$ years & & 43 \\
\hline \multirow[t]{4}{*}{ Follow-up period } & $3-5$ years & & \\
\hline & -3 years & & 57 \\
\hline & -4 years & & 37 \\
\hline & -5 years & & 70 \\
\hline \multicolumn{4}{|l|}{ Boost irradiation } \\
\hline & No & & 133 \\
\hline & Yes & $10 \mathrm{MeV}$ electron & 26 \\
\hline & & $7 \mathrm{MeV}$ electron & 5 \\
\hline
\end{tabular}

$\begin{array}{ccc}\text { No } 33 & & \\ \text { Yes } 131 & \text { Aromatase inhibitor } & 84 \\ & \text { Anti-estrogen } & 47\end{array}$

Chemotherapy

No 141

Yes $24 \quad$ Post surgery before radiotherapy 19

$\begin{array}{cc}\text { (EC 13, EC + D 4, ET 1, CEF 1) } & 19 \\ \text { Adjuvant (CMF 5) } & 5\end{array}$

Abbreviation: $\mathrm{E}=$ epirubicin, $\mathrm{C}=$ cyclophosphamide, $\mathrm{D}=$ docetaxel, $\mathrm{T}=$ paclitaxel, $\mathrm{F}=5 \mathrm{FU}, \mathrm{M}=$ methotrexate. 
were followed for 5 years after radiotherapy.

Whole breast irradiation was conventionally performed as follows: 4 MV X-ray, tangential field, wedge filter $15^{\circ}, 2 \mathrm{~Gy} /$ day, 5 fractions/week and total dose $50 \mathrm{~Gy}$. Additional boost irradiation was administered to 31 patients with positive or close surgical margins; $10 \mathrm{~Gy} / 5 \mathrm{fr}$ of 7 or $10 \mathrm{MeV}$ of electron beam radiation was additionally applied to the tumor bed.

This study was approved by our institutional reviewed board, and informed consent was obtained from the patients for the examinations.

\subsection{Methods}

The measurements were performed on the Multiprobe adaptor MPA: Mexameter ${ }^{\circledR}$ MX 18 (Integral, distributor for Courage + Khazaka Electronic GMBH, Germany). Mexameter ${ }^{\circledR}$ is an instrument that calculates melanin and erythema indices by using differences in the absorption between melanin and hemoglobin. Skin reflectance was measured by applying three different wavelengths $(568 \mathrm{~nm}$ : the absorption peak for hemoglobin, $660 \mathrm{~nm}$ : no absorption for hemoglobin, and $880 \mathrm{~nm}$ : almost no absorption for hemoglobin and melanin) to calculate the hemoglobin and melanin indices (the erythema index and the melanin index, respectively) [12].

Breast skin that was sufficiently distant from the surgical scar was selected for measurements' point in each patient in order to eliminate the skin changes caused by the surgical procedures. For comparison, the corresponding area of the non-irradiated breast was analyzed in the same manner. Four measurements were taken at each site in the sitting position; the average of the four measurements was used in the analysis. Measurements were taken before and at the end of radiotherapy and for 3 years or more after the completion of radiotherapy.

For both the erythema and the melanin indices, the ratio of the irradiated-side index to the non-irradiated-side index was calculated. The relationship between the changes in the index ratios and the length of time after radiotherapy was assessed. In the 164 patients who were followed for three years or more after the completion of radiotherapy, the time course for the erythema and melanin index ratios alternation was determined. For patients who had additional electron beam irradiation, the erythema and melanin indices were determined not only for the breast skin, but also for the skin where the electron beam irradiation was applied. A ratio of the 10-Gy boost irradiated-area index to the index of the irradiated side where boost irradiation was not applied was calculated, and the correlation between the index ratio and the length of time following radiotherapy was determined.

The index ratios at three years after radiotherapy were evaluated to examine the influences by endocrine therapy, chemotherapy and the age of the patient. Table 1 shows the details of each group.

\subsection{Statistical Analysis}

Paired t-test and one-way repeated measure ANOVA were used for the evaluation of significance in time course skin changes. Unpaired t-test and one-way factorial ANOVA and multiple comparison tests were used for the evaluation of influences in additional therapies and age. A p-value of less than 0.05 was taken as significant.

\section{Results}

\subsection{Time Course for Skin Color Alternation}

a) Erythema index ratio

Figure 1(a) shows time course of erythema index ratio. Erythema index ratio before irradiation had no remarkable differences in both breasts (mean \pm SE: $1.089 \pm 0.026$ ). Erythema index ratio also showed a significantly high value at the end of radiotherapy, then decreased gradually for three years after radiotherapy with statistical significance. However, no significance was recognized after three years.

We divided erythema index ratio values into three groups: high (1.2 or over), medium (under 1.2, and 0.8 and over), and low (under 0.8 ). Almost eighty percent of patients had high erythema index ratios at the end of radiotherapy and gradually decreased thereafter. On the other hand, low erythema index ratios appeared one year after radiotherapy and a quarter of our patients had low erythema index ratio three years after radiotherapy (Figure 1(b)).

b) Melanin index ratio

Figure 2(a) shows time course in melanin index ratio alternation. Melanin index ratios were low before radiation therapy (mean $0.900 \pm 0.028$ ); this signifies that the melanin index of the affected side is lower than that of the healthy side even before irradiation. Melanin index ratio at the end of radiotherapy showed no significant 


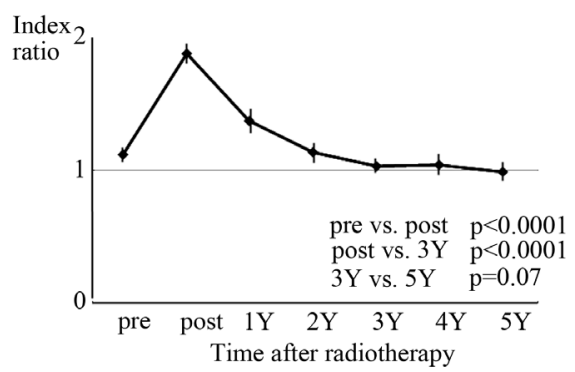

(a)

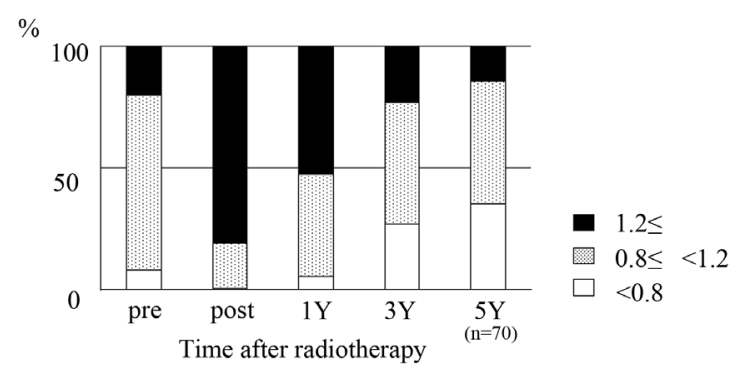

(b)

Figure 1. Time course of erythema index ratio. (a) Index ratio was high at the completion of radiotherapy, and declined significantly for three years after radiotherapy. Abbreviation: pre $=$ before radiotherapy, post $=$ at the completion of radiotherapy, 1, 2, 3, 4, $5 \mathrm{Y}=1,2,3,4,5$ years after radiotherapy. (b) Patients with low index ratios $(<0.8)$ account for almost a quarter at three years after radiotherapy.

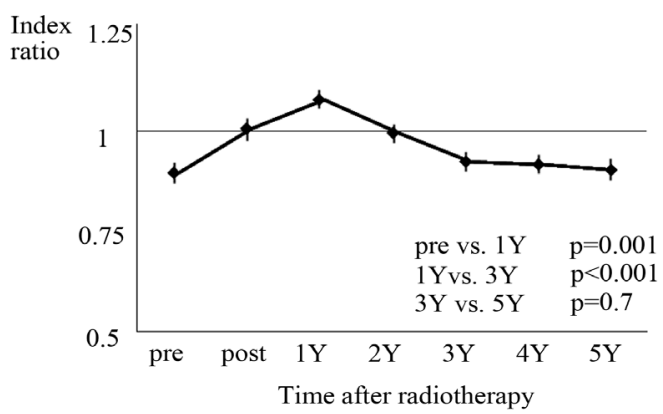

(a)

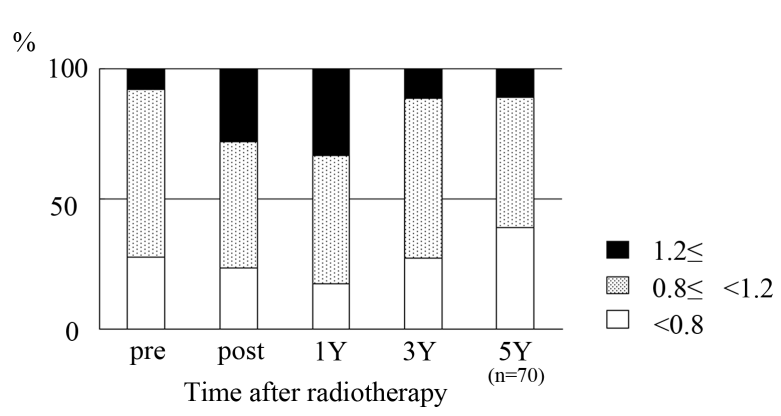

(b)

Figure 2. Time course of melanin index ratio. (a) The peak of index ratio is recognized at one year after radiotherapy, and index ratio declines significantly for three years after radiotherapy. (b) Patients with low index ratios $(<0.8)$ gradually increased after radiotherapy. Patients with low index ratios $(<0.8)$ account for almost thirty percent at three years after radiotherapy.

change compared to ratio of pre-radiotherapy. Melanin index ratio also increased one year after radiotherapy and then decreased for three years after radiotherapy in a statistically significant manner.

We divided melanin index ratio values in the same manner as erythema index ratio values. Figure 2(b) shows patients with low melanin index ratio increasing gradually after radiotherapy, and almost thirty percent of them had low melanin index ratio $(<0.8)$ at three years after radiotherapy.

c) Influence of boost irradiation

We examined chronological changes of index ratios in the boost irradiation field after radiation therapy.

Erythema index of 10-Gy boost irradiated area was approximately 1.7 times of that of non-boost area at the completion of radiotherapy, and it was still at a high value even after five years of radiation therapy (Figure 3(a)). Melanin index ratio showed the same pattern as that of the erythema index ratio (Figure 3(b)).

\subsection{Influences of Additional Therapies and Age}

We investigated chronic influences of some factors to erythema and melanin index ratio. We compared index ratios at three years after radiation therapy in each group.

a) Endocrine therapy

We divided endocrine therapy into three types: aromatase inhibitor, anti-estrogen ( \pm LH-RH agonist), and no endocrine therapy. Erythema index ratios at three years after radiotherapy of aromatase inhibitor group, anti-estrogen group, and no-endocrine group were $0.964 \pm 0.032,1.055 \pm 0.044$ and $1.078 \pm 0.048$ respectively. Erythema index ratios in aromatase inhibitor group were generally low; however, there was no statistically difference in these groups. Melanin index ratios in each group were as follows; $0.921 \pm 0.026,0.962 \pm 0.046$, and $0.887 \pm$ 0.044 respectively, and no significance was recognized as a result of different types of endocrine therapy (Figure 4(a)). 
b) Chemotherapy

Erythema index ratios three years after radiotherapy of patients with chemotherapy and without chemotherapy were $1.076 \pm 0.080$ and $1.002 \pm 0.023$ respectively. Melanin index ratios were $0.871 \pm 0.049$ and $0.936 \pm 0.023$ respectively. Neither erythema index ratio nor melanin index ratio had significant differences as a result of chemotherapy (Figure 4(b)).

b) Age at the start of radiotherapy

Erythema index ratio of patients who were fifty years old or above was $1.002 \pm 0.027$, and that of patients under fifty years old was $1.045 \pm 0.044$. Melanin index ratios were $0.919 \pm 0.023$ and $0.946 \pm 0.045$ respectively. The age of the patient (fifty and above, and under fifty) at the beginning of radiotherapy had no significant influences on each skin color index ratio at three years after radiotherapy (Figure 4(c)).

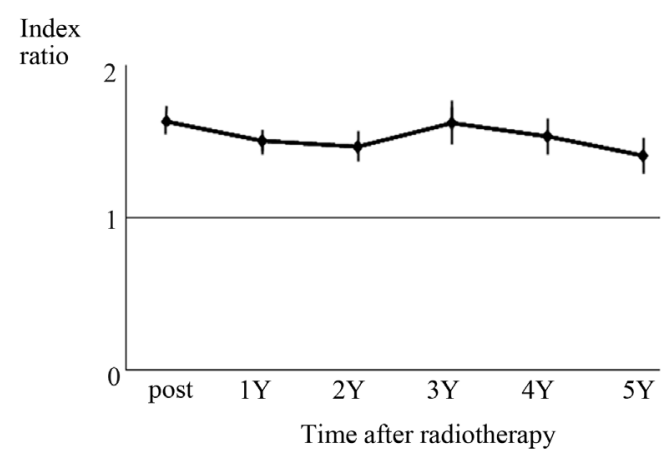

(a)

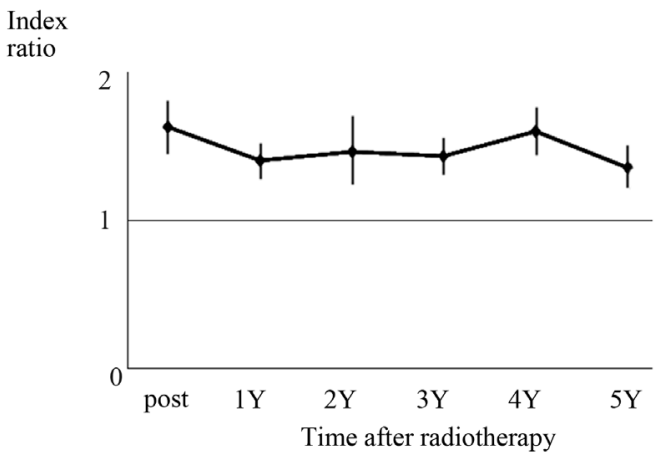

(b)

Figure 3. Time course of index ratio in the area received 10-Gy boost irradiation. (a) Erythema index ratio of boost area to non-boost area is 1.67 at the completion of radiotherapy, and it was 1.44 at five years after radiotherapy. (b) Melanin index ratio of boost area to non-boost area is 1.7 at the completion of radiotherapy, and it was 1.42 at five years after radiotherapy.

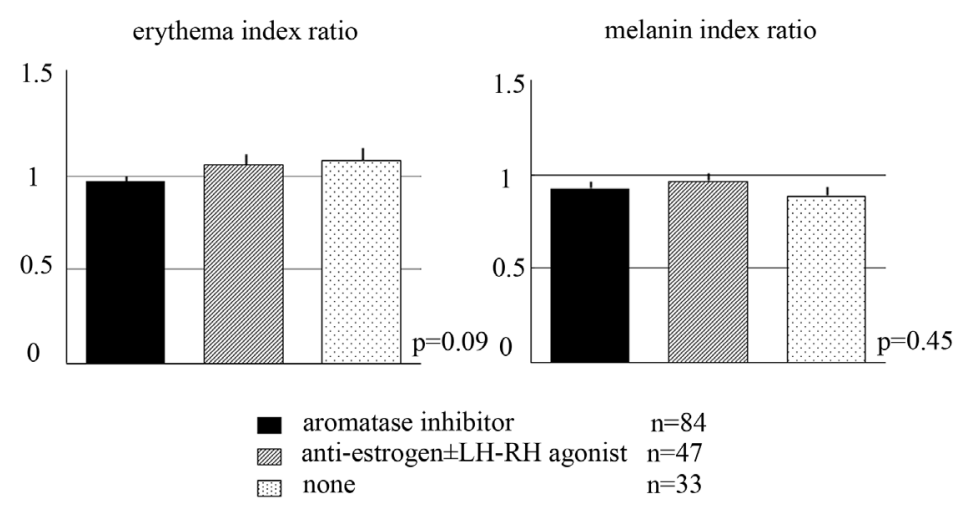

(a)

erythema index ratio

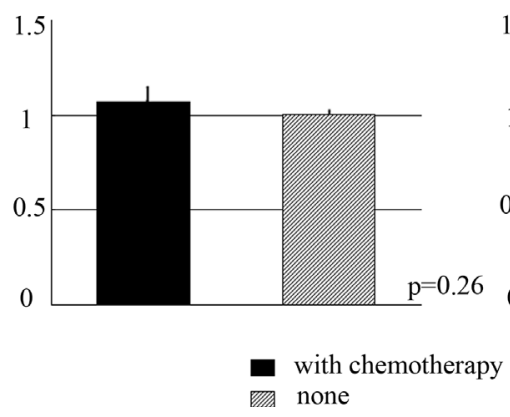

melanin index ratio

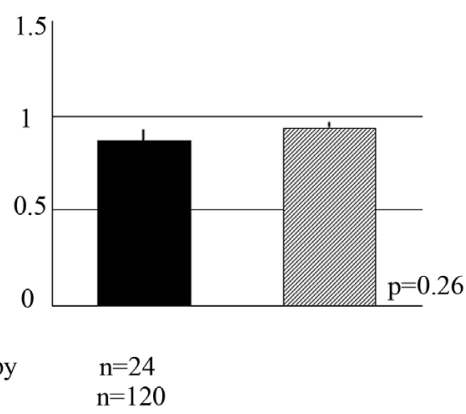

(b) 
erythema index ratio

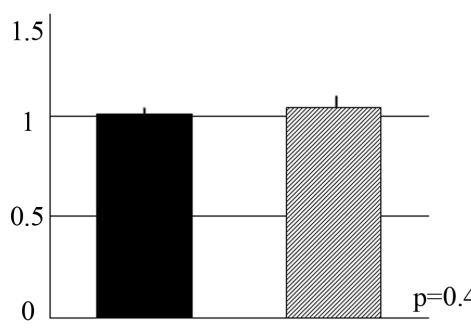

melanin index ratio

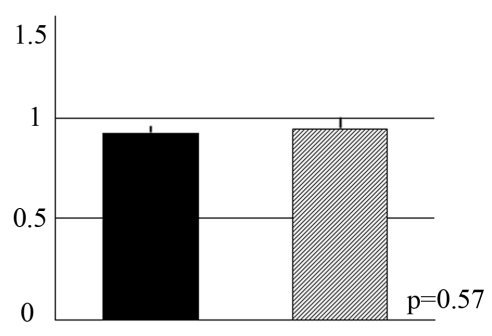

$\mathrm{n}=121$

$\mathrm{n}=43$

(c)

Figure 4. Comparison of index ratios at three years after radiotherapy. (a) Endocrine therapy. (b) Chemotherapy. (c) Patients' age. These factors have no significant influence on both index ratios.

\section{Discussion}

Breast conserving therapy is the treatment of choice for early breast cancers [1]-[3], and it is crucial to assess quality of life and adverse effects caused by surgery and irradiation in addition to survival or recurrent rates [4] [5]. In order to evaluate skin damages, the National Cancer Institute CTCAE v.4.0 [9] and LENT SOMA Toxicity Grading [10] are used as standard guidelines. However, there have not been any sufficient studies to evaluate skin reactions objectively. There is a possibility that results differ by subjective evaluation (by the investigator or by the time of evaluation); therefore, follow-up of the patient requires an objective evaluation.

Some investigators reported an objective assessment for radiation-induced skin reactions; for example, skin blood flow using a laser flow meter [13] [14], skin temperature by thermography [15], electrical resistance analysis [15], skin color by $L * a * b *$ values [16], and moisture analyses by Corneometer ${ }^{\circledR}[16]$.

We already reported an objective method to assess acute skin reactions following breast conserving therapy using Mexameter ${ }^{\circledR}$ (melanin-erythema index meter) in a previous study [11]. Skin color is normally affected by the amount of sub-epidermal melanin and the amount of dermal blood that is present. Mexameter ${ }^{\circledR}$ is a commercial-available instrument that calculates melanin and erythema indices by using differences in the absorption between melanin and hemoglobin [12]. The Mexameter ${ }^{\circledR}$ can be operated easily and the data can be obtained promptly by placing a probe with a built-in light emitter and light receiver on the skin surface. The Mexameter ${ }^{\circledR}$ and other similar devices have been already used to evaluate the effect of laser treatment [17] and skin reactions by UV radiation [18].

In this current study, we evaluated chronic skin reactions that followed breast conserving therapy. To the best of our knowledge, chronic assessments for irradiated skin by using an objective method have not been reported. Erythema index ratios were at high values at the end of radiotherapy and then gradually declined. Maximum changes in Melanin index ratio were observed one year after radiotherapy and then decreased thereafter. Both erythema and melanin index ratios one year after radiotherapy were significantly higher compared with before radiotherapy. Three years after radiotherapy, the index ratios returned to pre-radiation level, and both index values became lower than that of the non-irradiated side in a quarter of our cases. It is considered to reflect one chronic adverse effect, dyspigmentation, and it is suggested that whitening of the skin after radiation results from not only dyspigmentation but also decreased blood flow.

In our data, erythema index ratios significantly declined for three years after radiotherapy; however, there was no significance in the time course of index ratios between three to five years after radiotherapy $(p=0.07)$. There was also no statistical significance in melanin index ratios from three to five years after radiotherapy $(p=0.7)$. This suggests that skin color reactions caused by 50-Gy irradiation of breast conserving therapy are considered to become stable three years after radiotherapy.

However, 10-Gy boost irradiation resulted in different reactions in our study. It was documented that administration of 10-Gy boost irradiation did not deteriorate cosmetic results, but increased the occurrence of telangiectasia [19] [20]. Yoshida et al. [16] reported that at the end of radiotherapy, lower L* values (darker) and higher $\mathrm{a}^{*}$ values (more red) resulted from boost irradiation. In the present study, both erythema and melanin indices values were still higher than 50-Gy irradiated sites even five years after the completion of radiotherapy. It 
is considered that our method could explain severe skin damages caused by boost therapy objectively and quantitatively.

Endocrine therapy is important for breast cancer treatment, and 131 of our cases were administrated endocrine therapy. Skin color reactions at three years after radiotherapy were not influenced by endocrine therapy. Also chemotherapy had no significant effects on skin color reactions. Yoshida et al. [16] also reported no significant influences on skin color reactions by chemotherapy, but followed one year after radiotherapy. Neither patient's age at the beginning of radiation had statistical significance to both skin color indices at three years' post-radiotherapy. We chose as the cut-off for fifty years old close to the age of menopause. Forty five and fifty five years old were also examined as a cut-off, no significant difference showed (date not shown). Although there are a lot of factors including additional therapies and ages, it is considered that radiation therapy influences skin color reaction in breast conserving therapy the most. In other words, objective assessment of skin reactions is important for evaluation of adverse radiation effects.

\section{Conclusion}

This quantitative assessment using melanin-erythema index meter was considered useful in evaluating chronic skin color reactions after breast conserving therapy. It demonstrated that chronic skin color reactions following breast conserving therapy had recovered to pre-irradiation level for three years post irradiation except 10-Gy boost irradiated area.

\section{References}

[1] Early Breast Cancer Trialists' Group (2005) Effect of Radiotherapy and of Differences in the Extent of Surgery for Early Breast Cancer on Local Recurrence and 15-Year Survival: An Overview of the Randomized Trials. The Lancet, 366, 2087-2106. http://dx.doi.org/10.1016/S0140-6736(05)67887-7

[2] Fisher, B., Anderson, S., Bryant, J., Margolese, R.G., Deutsch, M., Fisher, E.R., Jeong, J.H. and Wolmark, N. (2002) Twenty-Year Follow-Up of a Randomized Trial Comparing Total Mastectomy, Lumpectomy, and Lumpectomy plus Irradiation for the Treatment of Invasive Breast Cancer. The New England Journal of Medicine, 347, 1233-1241. http://dx.doi.org/10.1056/NEJMoa022152

[3] Ohsumi, S., Sakamoto, G., Takashima, S., Koyama, H., Shin, E., Suemasu, K., Nishi, T., Nakamura, S., Iino, Y., Iwase, T., Ikeda, T., Teramoto, S., Fukutomi, T., Komaki, K., Sano, M., Sugiyama, K., Miyoshi, K., Kamio, T. and Ogita, M. (2003) Long-Term Results of Breast-Conserving Treatment for Early-Stage Breast Cancer in Japanese Women from Multicenter Investigation. Japanese Journal of Clinical Oncology, 33, 61-67. http://dx.doi.org/10.1093/jico/hyg014

[4] Engel, J., Kerr, J., Schlesinger-Raab, A., Sauer, H. and Hölzel, D. (2004) Quality of Life Following Breast-Conserving Therapy or Mastectomy: Result of a 5-Year Prospective Study. The Breast Journal, 10, 223-231. http://dx.doi.org/10.1111/j.1075-122X.2004.21323.x

[5] Takashima, S., Koyama, H., Kasumi, F., Kimijima, I., Ohkawa, T., Takatsuka, Y., Okumura, K., Kodama, H., Nishi, T., Sano, M., Fukutomi, T. and Kobayashi, S. (1995) Evaluation of the Quality of Life in Breast Cancer Patients Treated with Breast-Conserving Therapy. Journal of Japan Society for Cancer Therapy, 30, 1641-1652. (In Japanese with English Abstract)

[6] Hymes, S.R., Strom, E.A. and Fife, C. (2006) Radiation Dermatitis: Clinical Presentation, Pathophysiology, and Treatment. Journal of the American Academy of Dermatology, 54, 28-46. http://dx.doi.org/10.1016/j.jaad.2005.08.054

[7] Archambeau, J.O., Pezner, R. and Wasserman, T. (1995) Patholosiology of Irradiated Skin and Breast. International Journal of Radiation Oncology * Biology * Physics, 31, 1171-1185. http://dx.doi.org/10.1016/0360-3016(94)00423-I

[8] Hipewell, J.W. (1990) The Skin: Its Structure and Response to Ionizing Radiation. International Journal of Radiation Oncology * Biology * Physics, 57, 751-773. http://dx.doi.org/10.1080/09553009014550911

[9] National Cancer Institute. Common Terminology Criteria for Adverse Events (CTCAE) and Common Toxicity Criteria (CTC). http://ctep.cancer.gov/protocolDevelopment/electronic applications/ctc.htm

[10] Pavy, J.J., Denekamp, J., Letschert, J., Littbrand, B., Mornex, F., Bernier, J., Gonzales-Gonzales, D., Horiot, J.C., Bolla, M. and Bartelink, H. (1995) EORTC Late Effects Working Group. Late Effects Toxicity Scoring: The SOMA Scale. International Journal of Radiation Oncology * Biology * Physics, 31, 1043-1047. http://dx.doi.org/10.1016/0360-3016(95)00059-8

[11] Kawashima, M., Nozaki, M., Furuta, M., Nakamura, M., Komazaki, K. and Izawa, Y. (2007) Objective Assessment of Breast Skin Reactions after Breast-Conserving Therapy. JASTRO Japanese Society for Radiation Oncology, 19, 58-64. 
[12] Clarys, P., Alewaeters, K., Lambrecht, R. and Barel, A.O. (2000) Skin Color Measurements: Comparison between Three Instruments: The Chromameter ${ }^{\circledR}$, the Derma Specrometer ${ }^{\circledR}$, and the Mexameter ${ }^{\circledR}$. Skin Research and Technology, 6, 230-238. http://dx.doi.org/10.1034/j.1600-0846.2000.006004230.x

[13] Benediktson, K.P., Celebioglu, F. and Perkbeck, L.G. (1997) Influence of Radiation Therapy on Skin Circulation in Breast after Breast Conservative Surgery. Acta Oncologica, 36, 715-718. http://dx.doi.org/10.3109/02841869709001343

[14] Inomata, T., Ogawa, Y., Nishioka, A., Terashima, M., Kariya, S., Mesaki, K., Fukumoto, M. and Yoshida, S. (1995) Changes in Blood Flow and Skin Reaction Following Radiation Therapy. Nippon Acta Radiologica, 55, 58-64. (In Japanese with English Abstract)

[15] Sekine, H., Kobayashi, M., Honda, C., Aoki, M., Nakagawa, M. and Kanehira, C. (2000) Skin Reactions after Breast-Conserving Therapy and Prediction of Late Complications Using Physiological Functions. Breast Cancer, 7 , 142-148. http://dx.doi.org/10.1007/BF02967446

[16] Yoshida, K., Yamazaki, H., Takenaka, T., Tanaka, E., Kotsuma, T., Fujita, Y., Masuda, N., Kuriyama, K., Yoshida, M. and Nishimura, T. (2010) Objective Assessment of Dermatitis Following Post-Operative Radiotherapy in Patients with Breast Cancer Treated with Breast-Conserving Treatment. Strahlentherapie und Onkologie, 86, 621-629. http://dx.doi.org/10.1007/s00066-010-2134-1

[17] Dolotov, L.E., Sinichkin, Y.P., Tuchin, V.V., Utz, S.R., Altshuler, G.B. and Yaroslavsky, I.V. (2004) Design and Evaluation of a Novel Portable Erythema-Melanin-Meter. Lasers in Surgery and Medicine, 34, 127-135. http://dx.doi.org/10.1002/1sm.10233

[18] Takiwaki, H., Shirai, S., Kanno, Y., Watanebe, Y. and Arase, S. (1994) Quantification of Erythema and Pigmentation Using a Videomicroscope and a Computer. British Journal of Dermatology, 131, 85-92. http://dx.doi.org/10.1111/j.1365-2133.1994.tb08462.x

[19] Okumura, S., Mitsumori, M., Kokubo, M., Yamauchi, C., Kawamura, S., Oya, N., Nagata, Y. and Hiraoka, M. (2003) Late Skin and Subcutaneous Soft Tissue Changes after 10-Gy Boost for Breast Conserving Therapy. Breast Cancer, 10, 129-133. http://dx.doi.org/10.1007/BF02967637

[20] Romestaing, P., Lehingue, Y., Carrie, C., Coquard, R., Montbarbon, X., Ardiet, J.M., Mamelle, N. and Gérard, J.P. (1997) Role of a 10-Gy Boost in the Conservative Treatment of Early Breast Cancer: Result of a Randomized Trial in Lyon, France. Journal of Clinical Oncology, 15, 963-968.

\section{Submit or recommend next manuscript to SCIRP and we will provide best service for you:}

Accepting pre-submission inquiries through Email, Facebook, Linkedin, Twitter, etc

A wide selection of journals (inclusive of 9 subjects, more than 200 journals)

Providing a 24-hour high-quality service

User-friendly online submission system

Fair and swift peer-review system

Efficient typesetting and proofreading procedure

Display of the result of downloads and visits, as well as the number of cited articles

Maximum dissemination of your research work

Submit your manuscript at: http://papersubmission.scirp.org/ 